\title{
ПРОБЛЕМЫ ОБЕСПЕЧЕНИЯ ДОСТУПА К ЭКОЛОГИЧЕСКОЙ ИНФОРМАЦИИ НА РУБЕЖЕ ДВАДЦАТИЛЕТИЯ КОНСТИТУЦИИ РОССИИ
}

\begin{abstract}
Аннотация: В двадичатилетний юбилей российской Конституции актуализируется необходимость реализации и зачиты основных прав и свобод граждан. В статье рассмотрены правовые проблемы обеспечения доступа к экологической информации, включая реализацию конституционного права граждан на достоверную информацию о состоянии окружающей среды. Доступ к такой информации является условием реализации других конституиионных прав граждан - права на благоприятную окружающую среду, на возмещение ущерба, причиненного их здоровью или имуществу экологическим правонарушением, а также права на охрану здоровья. Гарантией доступа к экологической информации должно стать присоединение России к Орхусской конвенции. В этой связи высказаны предложения по совершенствованию экологического законодательства с учетом положительного зарубежного опыта. Проведен сравнительный анализ российского экологического, санитарно-эпидемиологического, информачионного и др. законодательства, а также зарубежного законодательства в области экологической информачии, обеспечивающего доступ к экологической информачии в соответствии с положениями Орхусской конвенции. Предложено совершенствование российского законодательства, направленное на правовое регулирование отношений в области экологической информации на системной основе. Обоснована необходимость разработки и принятия федерального закона об экологической информации, дана его структура, определен состав экологической информации, Сделаны предложения по приведению в соответствие с этим законом подзаконных нормативных правовых актов, а также повышению эффективности мер административной ответственности за правонарушения в области экологической информации и восполнения существующих пробелов.

Abstract: The necessity of the realization and protection of fundamental rights and freedom of citizens became actual in the twentieth anniversary of the Russian Constitution. The article examines the legal problems of ensuring access to environmental information, including the realization of the constitutional right of citizens to reliable information about the state of the environment. Access to such information is a condition for the realization of other constitutional rights of citizens - the right to a healthy environment, to damage compensation caused to their health or property by any environmental offense, as well as the right to health protection. The guarantee of access to the environmental information should constitute Russia's accession to the Aarhus Convention. Due to this fact there are some suggestions to improve environmental law, taking into account foreign experience. A comparative analysis of the Russian ecological, sanitary-epidemiological, information and other legislation, as well as foreign legislation in the field of environmental information, providing access to environmental information in accordance with the provisions of the Aarhus Convention, has been made. The improvement of Russian legislation, aimed at the legal regulation of relations in the field of environmental information in a systematic manner, has been proposed. The necessity of development and adoption of the federal law on environmental information is proved, its structure is given, the composition of environmental information is determined, the proposals have been made to align the sub-legislative regulatory legal acts with this law, as well as to increase the effectiveness of administrative responsibility for offenses in the field of environmental information and to fill the existing gaps.
\end{abstract}

Ключевые слова: экологическая информация, экологическое законодательство, Орхусская конвениия, конституиионные права, окружающая среда, доступ, гарантии, защита, закон, зарубежное законодательство Keywords: environmental information, environmental legislation, the Aarhus Convention, constitutional rights, the environment, access, guarantees, protection, law and foreign legislation. 
DOI: $10.7256 / 1811-9018.2014 .1 .10345$

При цитировании этой статьи сноска на доі обязательна

\section{Право и политика 1 (169) 2014}

опрос об обеспечении доступа к экологической информации не теряет своей актуальности вот уже на протяжении двадцати лет с момента принятия в 1993 г. Конституции России, провозгласившей человека, его права и свободы высшей ценностью Российской Федерации.

В числе признанных и гарантированных конституционных прав и свобод человека и гражданина согласно общепризнанным нормам международного права и в соответствии с Конституцией России выделяется право каждого на достоверную информацию о состоянии окружающей среды (ст. 42), являющуюся составной частью экологической информации.

Обеспечение доступа к такой информации является гарантией и условием реализации других конституционных прав граждан - права на благоприятную окружающую среду, на возмещение ущерба, причиненного их здоровью или имуществу экологическим правонарушением, а также права на охрану здоровья.

Необходимость государственной защиты этих прав наряду с другими конституционно закрепленными правами и свободами человека и гражданина во многом обусловлена неблагоприятным состоянием окружающей среды, что подтверждается официальными данными.

Как отмечается в государственной программе Российской Федерации «Охрана окружающей среды» на 2012 - 2020 годы, утвержденной распоряжением Правительства РФ от 27 декабря 2012 г. № 2552-p", примерно на 15 процентах территории Российской Федерации, где проживает 60 процентов населения, качество окружающей среды является неудовлетворительным, что обусловлено как текущим негативным воздействием хозяйственной и иной деятельности на окружающую среду, так и экологическим ущербом, нанесенным и накопленным в результате прошлой хозяйственной деятельности.

В 119 городах, где проживает порядка 55,1 млн. человек (53 \% городского населения России), уровень загрязнения атмосферного воздуха оценивается как высокий и очень высокий ${ }^{2}$.

В этих условиях для граждан становится жизненно необходимой информация о состоянии окружающей среды, которая зачастую не предоставляется органами власти, органами местного самоуправления, предприятиями загрязнителями. С такими проблемами,

\footnotetext{
${ }^{1}$ С3 РФ. 2013. № 1. Ст. 71.
}

${ }^{2}$ Государственный доклад «О состоянии и об охране окружающей среды в Российской Федерации в 2011 году» // http://www.mnr.gov. ru (обращение 5 ноября 2013 г.) например, столкнулись жители городского округа Электросталь и Ногинского района Московской области, которые были вынуждены проживать летом и осенью 2013 г. в условиях существенного загрязнения атмосферного воздуха, не получив каких-либо разъяснений по этому поводу от официальных властей³. Такие случаи не единичны.

Необходимость обеспечения доступа к экологической информации, реализации конституционного права граждан на достоверную информацию о состоянии окружающей среды диктуется не только внутренними предпосылками, но и внешними обстоятельствами. Речь идет о нерешенном до настоящего времени вопросе присоединения Российской Федерации к Конвенции Европейской экономической комиссии ООН о доступе к информации, участии общественности в процессе принятия решений и доступе к правосудию по вопросам, касающимся окружающей среды (Орхусской конвенции), которая была подписана 38 странами в г. Орхусе в Дании в 1998 году. Несмотря на то, что Российская Федерация активно участвовала в ее обсуждении, но не подписала этот важнейший международный документ.

С момента принятия конвенции 25 июня 2013 г. исполнилось пятнадцать лет. Однако и на сегодняшний день из государств-участников СНГ к конвенции не присоединились лишь Россия и Узбекистан. В этой связи принципиально важное значение приобретает принятие федерального закона о присоединении Российской Федерации к Орхусской конвенции, что предусмотрено п. 2 Плана действий по реализации Основ государственной политики в области экологического развития Российской Федерации на период до 2030 года, утвержденного распоряжением Правительства РФ от 18 декабря 2012 г. № 2423-p4. Разработка этого законопроекта в 2013 г. была возложена на Минприроды России совместно с заинтересованными федеральными органами исполнительной власти. Соответствующие предложения были представлены Минприроды России совместно с МИД России в марте 2013 г. в Правительство Российской Федерации в соответствии со ст. 21 Федерального закона от 15 июля 1995 г. № 101-Ф3 «О международных договорах Российской Федерации»5. По данному вопросу до настоящего времени отсутствует согласованная позиция заинтересованных сторон и он продолжает обсуждаться на

\footnotetext{
${ }^{3}$ http://www.electrostal.com/news/1393.html (обращение 5 ноября 2013 г.)

${ }^{4}$ СЗ РФ. 2012. № 52. Ст. 7561.

${ }^{5}$ СЗ РФ. 1995. № 29. Ст. 2757.
} 
различных уровнях, включая органы государственной власти и органы местного самоуправления, деловые и научные круги, общественность.

При этом перспективы присоединения России к Орхусской конвенции оцениваются неодинаково. Так, по мнению С.А. Боголюбова, на территории Российской Федерации конвенция пока не действует ввиду неготовности к этому российской правоохранительной и информационной систем. Вместе с тем им справедливо отмечается, что не будучи для нашей страны обязательной, эта Конвенция может служить ориентиром в требованиях информационного обеспечения граждан. В ряде федеральных нормативных правовых актов предусматриваются нормы об информационном обеспечении сфер деятельности, которые могут и должны быть всесторонне учтены при осуществлении экологической деятельности органов государственной власти и реализации права каждого на достоверную информацию о состоянии окружающей среды ${ }^{6}$.

Сравнительный анализ действующего российского законодательства и положений Орхусской конвенции показывает, с одной стороны, возможность присоединения в ней России, а, с другой, - необходимость внесения изменений и дополнений в некоторые законодательные акты экологического, административного и др. законодательства, а также принятие новых федеральных законов.

В числе основных положений Орхусской конвенции, являющихся предметом дискуссии при обсуждении вопроса о присоединении к ней России, является обеспечение доступа к экологической информации. Для этого необходимо законодательное закрепление определения понятия и состава такой информации, а также установление порядка ее предоставления гражданам, общественным организациям, обмена между органами государственной власти и органами местного самоуправления, правовое решение др. вопросов.

Несмотря на то, что в действующем российском законодательстве отсутствует понятие экологической информации, большое количество федеральных законов, относящихся к экологическому, санитарно-эпидемиологическому и др. законодательству, содержат правовые нормы, направленные на обеспечение права граждан, общественных организаций, юридических лиц на получение отдельных сведений, относящихся к экологической информации, в т.ч. конституционно закрепленного права каждого на достоверную инфор-

\footnotetext{
${ }^{6}$ Боголюбов С.А. Толкование экологических положений Конституции России в связи с ее юбилеем // Экологическое право. 2013. № 3. С. 7.
}

мацию о состоянии окружающей среды. Последнее право корреспондирует с общим правом на информацию, предусмотренным ч. 4 ст. 29 Конституции Российской Федерации, согласно которой каждый имеет право свободно искать, получать, передавать, производить и распространять информацию любым законным способом.

Право на достоверную информацию о состоянии окружающей среды нашло законодательное закрепление в Федеральном законе от 10 января 2002 г. № 7-Ф3 «Об охране окружающей среды» ${ }^{7}$ (ст. ст. 3, 11-13 и др.).

Однако, как следует из п. 3 ст. 2 Орхусской конвенции, экологическая информация включает в себя широкий круг сведений. Требования к большинству из таких сведений содержатся в российском экологическом законодательстве.

Так, Федеральным законом от 4 мая 1999 г. № 96-Ф3 «Об охране атмосферного воздуха» ${ }^{8}$ предусмотрены сведения о состоянии атмосферного воздуха, его загрязнении, об источниках загрязнения и вредного физического воздействия на него - ст. 3, 5, 6, 23, 29 и др.).

Сведения, входящие в состав экологической информации, содержатся и в др. федеральных законах, относящихся к экологическому, санитарно-эпидемиологическому, иным отраслям российского законодательства9. Большинство из этих сведений входят в перечень, предусмотренный Орхусской конвенцией. Однако в условиях отсутствия специального законодательно закрепленного понятия и состава экологической информации на практике возникают проблемы, связанные с ее предоставлением, обеспечением к ней доступа, что вызвано, в частности, следующим.

Федеральным законом от 27 июля 2006 г. № 262-Ф3 «Об информации, информационных технологиях и о защите информации» ${ }^{10}$ порядок доступа к информации разделяется в зависимости от категории доступа к ней: общедоступная информация и информация ограниченного пользования (п. 2 ст. 5).

В соответствии со ст. 8 Закона не может быть ограничен доступ к информации только о состоянии окружающей среды. Из этого следует, что остальные сведения, относящиеся к экологической информации по перечню сведений, указанных в Орхусской кон-

\footnotetext{
${ }^{7}$ СЗ РФ. 2002. № 2. Ст. 133.

${ }^{8}$ СЗ РФ. 1999. № 18. Ст. 2222.

${ }^{9}$ Подробнее см.: Выпханова Г.В. Экологическая информация: проблемы теории и законодательства / Под ред докт юрид наук, проф, заслуженного деятеля науки РФ М М Бринчука - М Издательский дом «Городец», 2009. С. 61-75.

${ }^{10}$ СЗ РФ. 2006. № 31 (1 ч.). Ст. 3448.
} 
DOI: $10.7256 / 1811-9018.2014 .1 .10345$

При цитировании этой статьи сноска на доі обязательна

Право и политика 1 (169) • 2014

венции, и предусмотренные указанными выше и др. федеральными законами, могут подпадать под режим ограниченного пользования.

Наряду с этим, в др. нормативных правовых актах указывается иной состав сведений. Так, согласно ст. 7 Закона РФ от 21 июля 1993 г. № 5485-1 «О государственной тайне» ${ }^{11}$ к сведениям, не подлежащим отнесению к государственной тайне и засекречиванию, относятся сведения: о чрезвычайных происшествиях и катастрофах, угрожающих безопасности и здоровью граждан, и их последствиях, а также о стихийных бедствиях, их официальных прогнозах и последствиях; о состоянии экологии, здравоохранения, санитарии.

В соответствии со ст. 5 Федерального закона от 29 июля 2004 г. № 98-Ф3 «О коммерческой тайне» ${ }^{12}$ режим коммерческой тайны не может быть установлен в отношении сведений о загрязнении окружающей среды, санитарно-эпидемиологической и радиационной обстановке.

Пунктом 1.3 Положения о порядке обращения со служебной информацией ограниченного распространения в федеральных органах исполнительной власти и уполномоченном органе управления использованием атомной энергии, утвержденного постановление Правительства РФ от 3 ноября 1994 г. № $1233^{13}$ не могут быть отнесены к служебной информации ограниченного распространения сведения о чрезвычайных ситуациях, опасных природных явлениях и процессах, экологическая, гидрометеорологическая, гидрогеологическая, демографическая, санитарноэпидемиологическая и другая информация, необходимая для обеспечения безопасного существования населенных пунктов, граждан и населения в целом, а также производственных объектов.

Данные примеры не являются единичными. Такие противоречия и несоответствия имеются и в других федеральных законах, а также подзаконных нормативных правовых актах. Отмеченные недостатки требуют устранения посредством законодательного закрепления понятия экологической информации, определения ее состава и правового режима.

Действующее российское экологическое и иное законодательство позволяет выделить в составе экологической информации следующие сведения:

\footnotetext{
${ }^{11}$ C3 РФ. 1997. № 41. Ст. 8220-8235.

${ }^{12}$ СЗ РФ. 2004. № 32. Ст. 3283.

${ }^{13}$ СЗ РФ. 2005. № 30 (ч. II). Ст. 3165.
}

о состоянии окружающей среды в целом, в том числе отдельных компонентов природной среды, природных объектов и комплексов, природно-антропогенных объектов, а также антропогенных объектов, в той степени, в какой на них воздействует или может воздействовать состояние окружающей среды и ее элементов;

- состоянии здоровья населения, безопасности людей, условиях их жизни, связанных с состоянием окружающей среды и использованием природных ресурсов;

- загрязнении окружающей среды и ее компонентов или ином негативном воздействии на них и здоровье населения, а также об объектах, источниках такого воздействия;

- об экологической угрозе или риске для здоровья и жизни людей, мерах по обеспечению безопасности (экологической, радиационной, промышленной, безопасности гидротехнических сооружений, генноинженерной деятельности и др.), авариях и причинах их возникновения и принятых мерах;

- о чрезвычайных ситуациях природного и техногенного характера, принимаемых и принятых мерах;

- состоянии природных ресурсов;

- нормативных правовых и иных актах (их проектах) в области охраны окружающей среды, рационального использования природных ресурсов и обеспечения экологической безопасности, а также мерах и последствиях их реализации;

- соглашениях в области природопользования и охраны окружающей среды;

- государственной экологической и иной политике, экологических и других прогнозах, программах и планах, оказывающих или способных оказать воздействие на состояние окружающей среды, здоровье, условия жизни и экологические права граждан;

- деятельности государственных органов, органов местного самоуправления, юридических и физических лиц, граждан-предпринимателей, связанной с использованием и распоряжением природными ресурсами, охраной окружающей среды, обеспечением экологической и иной безопасности, реализацией экологических прав граждан и юридических лиц;

- сведения, связанные с защитой экологических прав и законных интересов граждан и других субъектов.

Кроме того, в состав экологической информации, на наш взгляд, следует включать также информацию об источниках такой информации. В их числе, в частности, выделяются: нормативные правовые акты, 
экологический мониторинг, государственные кадастры природных ресурсов, экологический паспорт предприятия, радиационно-гигиенические паспорта организаций и территорий, декларация безопасности промышленного объекта, государственные доклады о состоянии окружающей природной среды в Российской Федерации.

При определении правового режима экологической информации необходимо наряду с регламентацией ее доступности решение и др. вопросов. В их числе установление сроков предоставления экологической информации в целом и относящихся к ней сведений, в частности, для обеспечения требования своевременности их предоставления.

Данный вопрос в действующем законодательстве решается неодинаково.

Так, ст. 12 Федерального закона от 2 мая 2006 г. № 59-Ф3 «О порядке рассмотрения обращений граждан Российской Федерации» ${ }^{14}$, в соответствии с которой письменное обращение, поступившее в государственный орган, орган местного самоуправления или должностному лицу согласно их компетенции, рассматривается в течение 30 дней со дня регистрации письменного обращения. Такой срок в определенных Законом случаях может быть продлен не более чем на 30 дней с уведомлением об этом заявителя. Данная норма распространяется на все виды информации, в том числе экологическую информацию, в отношении письменных обращений граждан (предложений, заявлений или жалоб).

В экологическом законодательстве установлены и иные, сокращенные, сроки предоставления информации. Например, пп. 33-35 Административного регламента предоставления Федеральным агентством водных ресурсов государственной услуги по предоставлению информации о гидротехнических сооружениях из Российского регистра гидротехнических сооружений и доступа к сведениям базы данных Российского регистра гидротехнических сооружений, утвержденного приказом Минприроды России от 31 октября 2012 г. № $358^{15}$, сроки предоставления таких сведений составляют от трех до пятнадцати дней, а в случае чрезвычайных ситуаций - в течение одного рабочего для, а, в некоторых случаях - одного часа. Другими административными регламентами установлены иные сроки исполнения государственной услуги

\footnotetext{
${ }^{14}$ С3 РФ. 2006. № 19. Ст. 2060.

15 Бюллетень нормативных актов федеральных органов
} исполнительной власти. 2013. № 19. федеральными органами исполнительной власти по предоставлению различных сведений, относящихся к экологической информации.

Данный вопрос также требует правового урегулирования на законодательном уровне в зависимости от видов экологической информации по степени срочности и формы. При нарушении установленных сроков экологическая информация должна считаться несвоевременной со всеми вытекающими из этого последствиями, включая привлечение лиц, обязанных предоставить такую информацию, к юридической ответственности.

В частности, статьей 8.5. Кодекса об административных правонарушениях Российской Федерации от 30 декабря 2001 г. № 195-Ф3 ${ }^{16}$ предусмотрена ответственность за сокрытие, умышленное искажение или несвоевременное сообщение полной и достоверной информации о состоянии окружающей среды и природных ресурсов, об источниках загрязнения окружающей среды и природных ресурсов или иного вредного воздействия на окружающую среду и природные ресурсы, о радиационной обстановке, а равно искажение сведений о состоянии земель, водных объектов и других объектов окружающей среды лицами, обязанными сообщать такую информацию.

Между тем данная статья, во-первых, содержит только часть сведений, относящихся к экологической информации и, во-вторых, не предусматривает применение административной ответственности за непредоставление такой информации и отказ от ее предоставления, тогда как такие случаи на практике является весьма распространенным.

Действующее законодательство (экологическое, информационное, и т.д.) включая законы и подзаконные нормативные правовые акты, имеет и др. недостатки (пробелы и противоречия), не позволяющие в полной мере обеспечить доступ к экологической информации, в т.ч. реализовать право граждан и общественных организаций на достоверную информацию о состоянии окружающей среды (отсутствие законодательно установленного перечня форм и источников экологической информации, единых требований ее предоставления и распространения, в т.ч. через средства массовой информации, порядка доступа к ней, декларативность обязанностей органов власти по обеспечению прав граждан на информацию о состоянии окружающей среды, иных сведений, входящих в состав экологической информации и т.д.).

\footnotetext{
${ }^{16}$ СЗ РФ. 2002. № 1 (ч. 1). Ст. 1.
} 


\section{Право и политика 1 (169) 2014}

Присоединение России к Орхусской конвенции требует устранения этих и др. недостатков посредством совершенствования российского законодательства. При этом следует учитывать невозможность их устранения в рамках информационного законодательства, поскольку в него включены лишь общие положения и предписания применительно к информации. В нем не определяется и не может быть определен правовой режим экологической информации в целом, и, кроме того, оно, находясь в состоянии совершенствования и развития, также не лишено противоречий и несоответствий.

Достижение указанных целей, преодоление существующих противоречий в законодательстве, порождающих на практике эколого-информационные правовые проблемы, возможно посредством разработки и принятия Федерального закона «Об экологической информации». Он должен базироваться на правовых нормах, содержащихся в информационном законодательстве, но одновременно отражать специфику правового режима и другие особенности, установленные применительно к экологической информации, обеспечению доступа к ней и т.д. в экологическом законодательстве, а также учитывать реальные потребности в правовом регулировании эколого-информационных отношений.

Сферу действия этого закона необходимо распространить на объективно существующие и активно развивающиеся общественные отношения, связанные с экологической информацией, ее обращением и возникающие в процессе природопользования и охраны окружающей среды.

Принятие такого закона обусловлено конституционно закрепленным правом каждого на достоверную информацию о состоянии окружающей среды, а также правом граждан и общественных организаций (объединений) на др. сведения, входящие в состав экологической информации, предусмотренным федеральными законами в составе экологического законодательства, необходимостью содействия им в осуществлении данного права, устранения противоречий и несоответствий действующего законодательства в этой области, исполнения международных обязательств, касающихся экологической информации.

При этом целесообразно использование положительного зарубежного опыта.

Так, например, в Австрии действует Федеральный закон об экологической информации ${ }^{17}$. В нем прямо предусмотрено право каждого на получение информа-

\footnotetext{
${ }^{17}$ The Federal environmental information Law (Umweltinformationsgesetz, BGBI 1993/495).
}

ции о состоянии вод, воздуха, почв, флоры и фауны, о выделении вредных веществ и превышении нормативов. Одновременно он закрепляет обязанности государственных органов предоставлять такую информацию.

Основу современной системы эколого-информационного законодательства Германии составляют Закон «Об экологической информации»; BGB1. I S. 3704 от 22 декабря 2004 г., вступивший в силу 14 февраля 2005 г., которым обязанность по информационному обеспечению общественности была распространена не только на региональные ведомства, но и на органы власти федерального уровня, а также Закон «О регулировании доступа к информации в Федеративной Республике Германия»; BGB1. I S. 2722 от 5 сентября 2005 г., вступивший в силу с 1 января 2006 г., обеспечивающий право на ознакомление с информацией органов власти ${ }^{18}$.

Законом Германии об экологической информации 2004 г. определен круг субъектов, включенных в процедуру обеспечения обязательного доступа к экологической информации. К ним относятся наряду с указанными в этом законодательном акте органами власти также физические и юридически лица частного права, исполняющие публично-правовые функции. Данным Законом определен порядок и условия предоставления экологической информации, установлены требования к ее источникам и др. ${ }^{19}$

В Великобритании действует специальный Закон об экологической информации и информации о безопасности 1988 г. Он регулирует вопросы информации, связанные с исполнением отраслевых законов о предупредительных противопожарных мерах, о здравоохранении и промышленной безопасности, о продовольствии и охране окружающей среды и др., в частности, посредством учреждения доступных общественности реестров соответствующей информации ${ }^{20}$.

Доступ к экологической информации как органов власти, так и заинтересованных физических и юридических лиц обеспечивается Законом Республики Таджикистан от 25 марта 2011 г. № 705 «Об экологической информации» ${ }^{21}$. В нем закреплено понятие экологической информацией, определен ее состав. В рамках экологической информации выделяется общая и

\footnotetext{
${ }^{18}$ См.: Волков К.В. Правовое регулирование доступа к экологической информации (сравнительно-правовой анализ): Дис. ... канд. юрид. наук. М., 2009. С. 119, 139.

19 Там же.

${ }^{20}$ Environment and Safety Information Act 1988 Chapter 30 http: // www.opsi.gov.uk/acts/acts1988/ukpga_1988003

${ }^{21} \mathrm{http}$ :// base.spinform.ru/show_doc.fwx?Rgn= 43140 .
} 
специальная экологическая информация, дан перечень экологических информационных ресурсов. Правовой режим экологической информации включает в себя ряд требований, связанных с доступом к ней (общим и специализированным) и его ограничениями. При этом закреплен перечень экологической информации, ограничение доступа к которой не допускается. Законом предусмотрены общие требования к срокам предоставления экологической информации физическим и юридическим лицам, государственным органам либо иным государственным организациям ${ }^{22}$.

Особо следует выделить экологическое законодательство Республики Казахстан как отражение его гармонизации с положениями Орхусской конвенции, выражающейся в том, что в Кодекс Республики Казахстан от 9 января 2007 года № 212-III «Экологический кодекс Республики Казахстан» ${ }^{23}$ включена самостоятельная глава 21. Экологическая информация.

Для России представляют интерес следующие положения Экологического кодекса Республики Казахстан:

- виды экологической информации, которые государственные органы в соответствии с их компетенцией распространяют посредством размещения в Интернете и применения иных общедоступных информационнокоммуникационных средств (п. 5 ст. 160);

- состав Государственного фонда экологической информации (п. 4 ст. 161);

- составление комплексного научно-справочного сборника картографических материалов Национального экологического атласа (ст. 162);

- правила доступа к экологической информации (ст. 163);

- основания отказа в предоставлении экологической информации, право обжалования отказа в предоставлении, непредоставление, предоставление неполной или недостоверной экологической информации, а также неправомерное отнесение общедоступной экологической информации к информации с ограниченным доступом в вышестоящий государственный орган и (или) должностному лицу или в суд (ст. 167) и др.

Опыт Казахстана, Таджикистана и других государств, реализующих сегодня базовые положения Орхусской конвенции, может быть использован для совершенствования российского законодательства, в котором вопросы доступа к экологической

\footnotetext{
${ }^{22}$ Подробнее см.: Минбалеев А.В. Доступ к экологической информации по законодательству Республики Таджикистан // Экологическое право. 2012. № 2. С. 25 - 28.

${ }^{23}$ Ведомости Парламента Республики Казахстан. 2007. № 1. Ст. 1.
}

информации продолжают оставаться на уровне общих норм, закрепляющих право на благоприятную окружающую среду и достоверную информацию о ее состоянии.

Зарубежное законодательство в области экологической информации и практика его применения подтверждают целесообразность разработки и принятия Федерального закона «Об экологической информации», в котором необходимо предусмотреть следующий круг вопросов:

- дать понятие и состав экологической информации, а также открытый перечень ее источников;

- определить понятие и виды эколого-информационных ресурсов, право собственности на них;

- закрепить состав государственных экологоинформационных ресурсов, установив требования к их правовому режиму, исходя из публично-правовых начал регулирования;

- $\quad$ включить принципы правовой регламентации отношений в области экологической информации (открытости, доступности, достоверности, обоснованности, своевременности, полноты и др.);

- урегулировать отношения доступа к экологической информации граждан и юридических лиц способами, предусмотренными информационным, экологическим и иным законодательством, в том числе закрепить право граждан и экологических общественных организаций (объединений) на оперативное и бесплатное получение сведений, относящихся к экологической информации, и соответственно обязанности органов государственной власти, органов местного самоуправления, иных субъектов по обеспечению доступа к такой информацией;

- определить порядок предоставления экологической информации, предусмотрев перечень случаев ее незамедлительного (экстренного) бесплатного предоставления, возможность предоставления (получения) экологической информации в конкретных случаях на платной основе по обоснованным расценкам, варианты отказа ее предоставления по определенным основаниям с правом обжалования в судебном порядке непредоставления, отказа в предоставлении экологической информации;

- закрепить требования к эколого-информационным системам (единства, сопоставимости, совместимости, взаимодействия, согласованности и координации всех ее составных частей, используемых методов и методик сбора, анализа и оценки экологической информации и др.), определить порядок их создания и функционирования; 
DOI: $10.7256 / 1811-9018.2014 .1 .10345$

При цитировании этой статьи сноска на доі обязательна

\section{Право и политика 1 (169) • 2014}

- регламентировать порядок и условия сбора, передачи, распространения и обмена экологической информацией;

- $\quad$ предусмотреть защиту права на экологическую информацию и привлечения к ответственности за нарушение законодательства в области экологической информации.

Принятие в России федерального закона об экологической информации позволит привести в соответствии с ним законы и подзаконные нормативные правовые акты экологического и другого законодательства, содержащие правовые нормы, имеющие непосредственное отношение либо касающиеся экологической информации.

В этой связи потребуется принятие ряда подзаконных нормативных правовых актов, направленных на реализацию положений Федерального закона «Об экологической информации», устанавливающих, в частности, порядок обращения государственных эколого-информационных ресурсов, определяющих перечни видов информации, передаваемой в обязательном порядке в состав государственных эколого-информационных ресурсов и др.

Наряду с этим потребуется внесение изменений и дополнений в действующие федеральные законы, в первую очередь в Федеральный закон «Об охране окружающей среды» в части, касающейся терминов и понятий, посредством введения в текст формулировок, отвечающих требованиям Орхусской конвенции и согласованной с нормами иных федеральных законов.

Для повышения эффективности мер административной ответственности за правонарушения в области экологической информации и восполнения существующих пробелов потребуется расширение содержание ст. 8.5 КоАП РФ путем включения в нее дополнительных оснований применения административного взыскания - за непредоставление экологической информации и необоснованный отказ от ее предоставления, оставление запроса без рассмотрения.

Кроме того, представляется необходимым принятие Постановление Пленума Верховного Суда РФ «О практике применения судами законодательства об экологической информации».

Тем самым будет создана система законодательства в области экологической информации, направленная на правовое регулирование отношений в этой области на комплексной основе. В случае принятия Экологического кодекса РФ в нем необходимо предусмотреть в положения предлагаемого законопроекта.

Эти меры являются необходимым следствием присоединения России к Орхусской конвенции. Вместе с тем сравнительная характеристика положений Орхусской конвенции и российского экологического законодательства позволяет сделать вывод о возможности присоединения России к Конвенции на современном этапе.

Во-первых, в нормах российского экологического и смежного с ним законодательства содержится практически весь перечень видов сведений, включенных в состав экологической информации, предусмотренных Конвенцией.

Во-вторых, право на доступ к экологической информации юридически формально закреплено в российском конституционном, экологическом и ином законодательстве в многочисленных актах самого высшего уровня.

В-третьих, в российском законодательстве доступными являются следующие источники экологической информации, названные в Конвенции: государственные доклады об охране и о состоянии окружающей среды; тексты законодательных актов по вопросам окружающей среды или имеющим к ней отношение; документы по вопросам политики, планы и программы и др.

В-четвертых, систематичность сведений обеспечивается существующей в России системой экоучета, а ответственность за отказ в предоставлении экологической информации предусмотрена российским уголовным и административным законодательством.

Кроме того, достижению совместимости российского законодательства в области экологической информации с положениями Орхусской конвенции способствует активизация начатого в России процесса обеспечения доступа к информации (в том числе экологической) о деятельности государственных органов и органов местного самоуправления, а также доступа к информации о деятельности судов в соответствии со специальными федеральными законами.

Таким образом, имеются не только потребности, но и реальные возможности присоединения России к Орхусской конвенции, что будет способствовать правовому регулированию отношений в области экологической информации на единой правовой основе, выработанной мировым и европейским сообществом. Присоединение к Конвенции отвечает национальным интересам, будет способствовать решению ряда природоохранных проблем в европейском регионе и повысит статус нашей страны как правового государства, тем более, что Россия в составе МПА приняла модельный закон МПА «О доступе к экологической информации», базирующийся на нормах этой Конвенции.

Присоединение России к Орхусской конвенции будет способствовать: 
DOI: $10.7256 / 1811-9018.2014 .1 .10345$

При цитировании этой статьи сноска на doi обязательна

Человек и окружающая среда

- развитию гражданского общества;

- увеличению ответственности власти, бизнеса и общественности за принимаемые решения;

- нахождению баланса публичных и частных интересов;

- соблюдению конституционных прав граждан;

- улучшению качества окружающей среды.

Присоединение к Орхусской конвенции обусловлено также необходимостью обеспечения Россией исполнения международных договоренностей и обязательств по охране окружающей среды, касающихся обмена различными сведениями, относящимися к экологической информации, информирования общественности, решения др. эколого-информационных вопросов.

\section{Библиография:}

1. Боголюбов С.А. Толкование экологических положений Конституции России в связи с ее юбилеем // Экологическое право. 2013. № 3. С. 2-11.

2. Волков К.В. Правовое регулирование доступа к экологической информации (сравнительно-правовой анализ): Дис. ... канд. юрид. наук. М., 2009. - 217 с.
3. Выпханова Г.В. Экологическая информация: проблемы теории и законодательства / Под ред докт юрид наук, проф, заслуженного деятеля науки РФ М М Бринчука-М Издательский дом «Городец», 2009-240 с

4. Минбалеев А.В. Доступ к экологической информации по законодательству Республики Таджикистан // Экологическое право. 2012. № 2. С. 25-28.

\section{References (transliteration):}

1. Bogolyubov S.A. Tolkovanie ekologicheskikh polozhenii Konstitutsii Rossii v svyazi s ee yubileem // Ekologicheskoe pravo. 2013. № 3. S. 2-11.

2. Volkov K.V. Pravovoe regulirovanie dostupa k ekologicheskoi informatsii (sravnitel'no-pravovoi analiz): Dis. ... kand. yurid. nauk. M., 2009. - 217 s.

3. Vypkhanova G.V. Ekologicheskaya informatsiya: problemy teorii i zakonodatel'stva / Pod red dokt yurid nauk, prof, zasluzhennogo deyatelya nauki RF M M Brinchuka-M Izdatel'skii dom «Gorodets», 2009-240 s

4. Minbaleev A.V. Dostup k ekologicheskoi informatsii po zakonodatel'stvu Respubliki Tadzhikistan // Ekologicheskoe pravo. 2012. № 2. S. 25-28. 